\title{
The Role of Increase of Entropy of Magma In the Chamber Triggering Eruption in Volcanoes
}

\author{
Dr.(Prof.) V.C.A. Nair* \\ Educational Physicist, Distinguished Alumnus, Chancellor-Designated Resource Person in the \\ Area of Physics and Research Guide for Physics at JJT University, Jhunjhunu, Rajasthan-333001, India \\ Research Scholar for the Degree of Doctor of Science (D.Sc) in Madurai Kamaraj University, \\ Madurai-625021, Tamil Nadu, India \\ *nairvca39@gmail.com
}

\begin{abstract}
The Paper begins with elementary concepts of Entropy from basic thermodynamic considerations. Entropies of Magma in the Chamber, the intruding magma and the entropy after intrusion are considered. The physical state of affairs after intrusion leading to eruption is dealt with in a systematic manner. In the Conclusion, without going into details, the author has just mentioned the name of Edward Lorenz of Chaos theory
\end{abstract}

Keywords: Chaos, Convection of Magma, Entropy, Eruption, Isochoric process, Magma, Magma Chamber, Magma Intrusion, Principle of Increase of Entropy, Specific heat, Volume of Magma Chamber

\section{INTRODUCTION}

1.1 Preamble: The Earth's Mantle is just an ocean of Magma occupying over $70 \%$ of its volume whereas the magma reservoirs and chambers are just lakes of magma, may be even larger than a lake in size. The material of magma with which we are concerned is usually at about $1000^{\circ} \mathrm{C}$ and remains as fluid before it gets solidified as lava after eruption. Being a fluid, laws of thermodynamics and fluid mechanics involving physical properties such as convection, conductivity, viscosity, entropy, etc. can be very well applied.

\section{Review of Literature}

1.2 Elementary Concepts of Entropy: The term entropy was coined in 1865 by the German physicist Rudolf Clausius (Fig.3) from Greek $e n-=$ in + trope $=$ a turning (point). The word reveals an analogy to energy and etymologists believe that it was designed to denote the form of energy that any energy eventually and inevitably turns into -- a useless heat. The idea was inspired by an earlier formulation by a French military scientist and physicist, Sadi Carnot (Fig.1) of what is now known as the second law of thermodynamics. The Austrian physicist Ludwig Boltzmann and the American scientist Willard Gibbs put entropy into the probabilistic setup of statistical mechanics (around 1875). This idea was later developed by Max Planck. Entropy was generalized to quantum mechanics in 1932 by John von Neumann . Later this led to the invention of entropy as a term in probability theory by Claude Shannon (1948), in a joint book with Warren Weaver, that provided foundations for information theory.

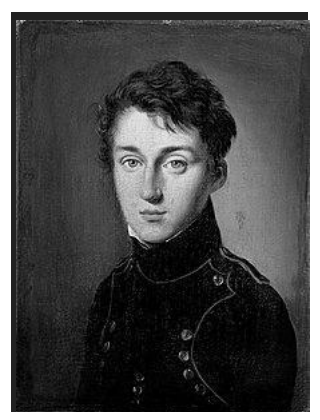

Fig.1. Sadi Carnot (1796-1832)

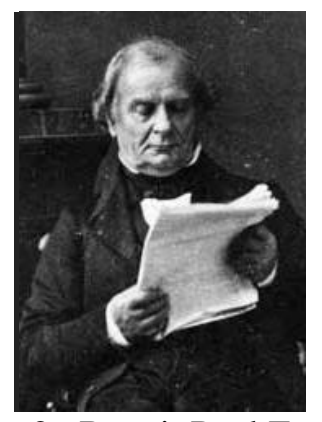

Fig.2. Benoit Paul Emile Clapeyron (1799-1864)

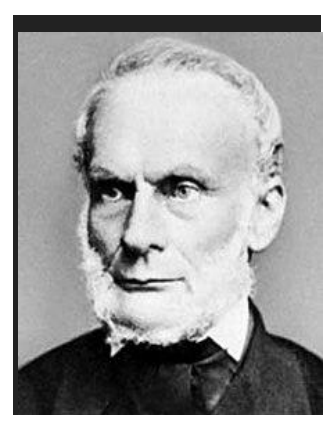

Fig.3 Rudolf Clausius (1822-1888) 


\section{International Advanced Research Journal in Science, Engineering and Technology}

Vol. 6, Issue 7, July 2019

The concept of entropy in dynamical systems was introduced by Andrei Kolmogorov and made precise by Yakov Sinai in what is now known as the Kolmogorov-Sinai entropy.The formulation of Maxwell's paradox by James C. Maxwell (around 1871) triggered a search for the physical meaning of information, which resulted in the finding by Rolf Landauer (1961) of the heat equivalent of the erasure of one bit of information, which brought the notions of entropy in thermodynamics and information theory together.

The term entropy is now used in many other sciences (such as sociology), sometimes distant from physics or mathematics, where it no longer maintains its rigorous quantitative character. Usually, it roughly means disorder, chaos, decay of diversity or tendency toward uniform distribution of kinds.

1.2.1 The Formula: Benoit Paul Emile Clapeyron (Fig.2) and Rudolf Clasius (Fig.3) in the year 1843 developed the idea of a reversible process, already suggested by Carnot and made a definitive statement of Carnot's principle, what is now known as the second law of thermodynamics. These foundations enabled him to make substantive extensions of Clausius' work, including a formula, now known as the ClausiusClapeyron relation, which characterizes the phase transition between two phases of matter.

The enthalpy, $\mathrm{H}$ of a thermodynamic system is defined as

$\mathrm{H}=\mathrm{U}+\mathrm{W}$, where $\mathrm{U}$ is the internal energy and $\mathrm{W}$ is the work done which is further equal to $\mathrm{P} \mathrm{V}$. Hence, $\mathrm{H}=\mathrm{U}+\mathrm{PV}$

[6] In most of the chemical reactions the work term PV is much smaller than the internal energy and hence $\mathrm{H}=\mathrm{Q}$ where we have replaced $\mathrm{U}$ by the alphabet, $\mathrm{Q}$ meaning the quantity of heat or the Heat-content of the system. Now, the Clasius-Clapeyron equation is given by

$$
: \frac{\mathrm{dP}}{\mathrm{dT}}=\frac{1}{\mathrm{~T}}\left(\frac{\Delta \mathrm{Q}}{\Delta \mathrm{V}}\right)
$$

where $\mathrm{T}$ is the absolute temperature. $\Delta \mathrm{V}$ appears in the above equation in spite of our neglecting the work done in the previous paragraph. This is because $\Delta \mathrm{V}$ is an infinitesimal tending to zero but not equal to zero and hence to be considered in derivations. Re-arranging equation (1), we can write

$$
\Delta \mathrm{V} \frac{\mathrm{dP}}{\mathrm{dT}}=\frac{\Delta Q}{\mathrm{~T}}
$$

The quantity on the right of equation (2) is called 'Entropy' or more precisely the change in entropy of the system and is denoted by $\Delta \mathrm{S}$ and writing in the integral form, we have

$$
\Delta \mathrm{S}=\int^{\mathrm{T}}\left(\frac{\mathrm{dQ}}{\mathrm{T}}\right) \ldots \ldots \ldots \ldots \ldots \ldots
$$

Avoiding differentials, we may write

$$
S=\left(\frac{Q}{T}\right)
$$

is the formula for entropy the SI unit for which is $\frac{\mathrm{J}}{\mathrm{K}}$

Equation (4) is an important formula for us. We shall work out the entropy of magma under different physical situations. The formula shows that increasing temperature will not have any effect on the entropy because as temperature is increased, the heat-content in the system $\mathrm{Q}=$ mass $\mathrm{x}$ Specific heat $\mathrm{x}$ temperature will be increased at the same time. In other words, as $\mathrm{T}$ appears both in the numerator and denominator of the equation, entropy S simply becomes equal to mass multiplied by specific heat making the unit of entropy dimensionally correct. Thus the only way to increase the entropy of magma in the chamber is to increase its heat-content by adding more mass at the same temperature something like adding to a cup of tea little more from the kettle, both the tea being at the same temperature. The essence this paper is to make the increase of entropy as a trigger for eruption. The increase of entropy is justified from the literature that follows. We have to add some disorder to an already existing disorder and make the system uncontrollable favoring an eruption.

\section{ENTROPY OF A MIXTURE}

2. Entropy of Mixture: As we will be dealing with situations of entropies before and after magma entering the chamber, [5] has dealt with situations of entropies when two gases mix with each other. I would like to produce below in italics exactly what the author has given in his classical book.

Sec.5 (a) "Let us suppose that we have two perfect gases side by side in two perfectly conducting vessels so that they are always at the same temperature but in general at different pressures. Suppose that one or both of the gases undergoes a reversible change of volumes, the temperature of the two remaining always 


\section{International Advanced Research Journal in Science, Engineering and Technology}

Vol. 6, Issue 7, July 2019

remaining the same by conduction and no heat entering from outside. The change in entropy of the first gas $d S_{1}$ is given by

$$
d S_{1}=\left(\frac{d Q_{1}}{d T_{1}}\right)
$$

and in the same time the change of entropy of the second gas is given by

$$
d S_{2}=\left(\frac{d Q_{2}}{d T_{2}}\right) .
$$

Since $T_{1}=T_{2}$ and $\left(d Q_{1}+d Q_{2}\right)=0$, we have

and for a finite change of condition,

$$
\left(d S_{1}+d S_{2}\right)=0
$$

$$
\left(S_{1}+S_{2}\right)=\text { Constant }
$$

That is to say, the sum of the entropies of the two gases remains constant",

2.1 The Principle of Increase of Entropy: The author [5] further says in the final paragraph of the sec.5 that "Every physical and chemical process which takes place in nature proceeds in such a way that the total entropy of all the bodies taking any part in the process is increased. In the limiting case of a reversible process the total entropy remains constant. This is the principle of increase of entropy."

2.2 Calculation for entropy of magma: The formula for entropy, $S$ given by equation (4) can be used to work out the entropies of thermal systems. The quantity $\mathrm{Q}$ which is the heat-content of the system is the product of the mass, $\mathrm{m}$, the specific heat, $\mathrm{c}$ and the absolute temperature, T. That is,

$\mathrm{Q}=\mathrm{mcT} \ldots \ldots \ldots \ldots \ldots \ldots$ (9)
expressed in Joules. The entropy, $\mathrm{S}=\frac{\mathrm{Q}}{\mathrm{T}}=\frac{\mathrm{mct}}{\mathrm{T}}=\mathrm{m} \mathrm{c}$ as $\mathrm{T}$ appearing both in the numerator and denominator. Therefore,

$$
\mathrm{S}=\mathrm{mc}
$$

Now, for the calculation of entropy of magma in a certain chamber, we need both the mass and specific heat of magma. The specific can be obtained from tables, but for the mass, we have to first of all select the volcano and its chamber. After once the chamber is selected, the volume can be found out from the net and knowing the density, mass can be worked out as it is the product of volume and density

We follow Nobuo Geshi, et.al [4] to select a volcano and its chamber: Estimated volumes of magma chambers associated with caldera collapse are $3-10(\mathrm{~km})^{3}$; for Vesuvius 79 AD to 3000 to $10,500(\mathrm{~km})^{3}$. $=10,500 \times 10^{9}$ cubic meter $=1.05 \times 10^{13}$ cubic meter

[2] Ken Jorgustin has considered 5 volcanoes of Volcano Explosive Index (VEI) from 4 to 8 and the same is given in TableNo. 1

Table No.1

\begin{tabular}{|c|c|l|l|}
\hline No & $\begin{array}{c}\text { Volcano } \\
\text { Explosive } \\
\text { Index (VEI) }\end{array}$ & \multicolumn{1}{|c|}{ Volume } & \multicolumn{1}{c|}{ Size comparable to } \\
\hline 1 & 4 & 1 Billion cubic meters & Size of Eiffel Tower, Paris, France \\
\hline 2 & 5 & 10 Billion cubic meters & $\begin{array}{l}\text { As tall as world's tallest building, Burj Khalija at } \\
\text { Dubai }\end{array}$ \\
\hline 3 & 6 & 100 Billion cubic meters & Equal to the volume of New York City, US \\
\hline 4 & 7 & 1 Trillion cubic meters & Equal to volume of Boston city, US \\
\hline 5 & 8 & 10 Trillion cubic meters & $\begin{array}{l}\text { Equal to Sacramento, San Jose and San Francisco, } \\
\text { US put together }\end{array}$ \\
\hline
\end{tabular}

Instead of selecting a volcano at random, let us choose one of large VEI, that is the fifth one in the serial. Let us convert the volume into cubic meters. One trillion $=10^{12}$ and hence 10 trillion cubic meter $=10^{13}$ 


\section{International Advanced Research Journal in Science, Engineering and Technology}

Vol. 6, Issue 7, July 2019

cubic meter. This volume almost coincides with that of the volume of chamber of Vesuvius. For any future calculation, we may take the volume as $10^{13}$ cubic meter. The formula for entropy given by equation (4a) requires mass, $\mathrm{m}$ which is the product of volume, $\mathrm{V}$ and density, $\rho$ and specific heat, $\mathrm{c}$. Thus, the formula can be re-written as

$$
\mathrm{S}=\mathrm{V} \rho \mathrm{c}
$$

For density and specific heat, the following is what is obtained from Google Search [1]

"The density, specific heat, viscosity, and thermal conductivity of a typical basaltic magma at $1200 \mathrm{C}$ at low pressure are $2600 \mathrm{~kg} / \mathrm{m} 3,1450 \mathrm{~J} / \mathrm{kg} \mathrm{K}, 100 \mathrm{~Pa} \mathrm{~s}$, and $0.6 \mathrm{~W} / \mathrm{m} \mathrm{K}$, respectively."

Thus the entropy of magma at $1200^{\circ} \mathrm{C}$ in the magma chamber of volcano Vesuvius is $\mathrm{S}_{1}=10^{13} \times 2600 \times 1450=377 \times 10^{17} \frac{\mathrm{J}}{\mathrm{K}}$. That is,

$$
\mathrm{S}_{1}=377 \times 10^{17} \frac{\mathrm{J}}{\mathrm{K}}
$$

\section{INTRUSION OF MAGMA}

3. Magma Intrusion: Now, let us consider the entry of a small quantity of magma from the mantle to the magma chamber of the volcano as shown in Fig.4. We call this as the Magma Intrusion. The term, 'small quantity' has to be clarified. Some $100 \mathrm{~kg}$ or even $1000 \mathrm{~kg}$ of magma into such a voluminous chamber will be something like a rat entering a manhole. It will not create any effect. How much large quantity is the question now. In order to have some good effect, let us assume that magma equal to some one-hundredth of magma already in the chamber enters from the mantle and make it

slightly more massive.

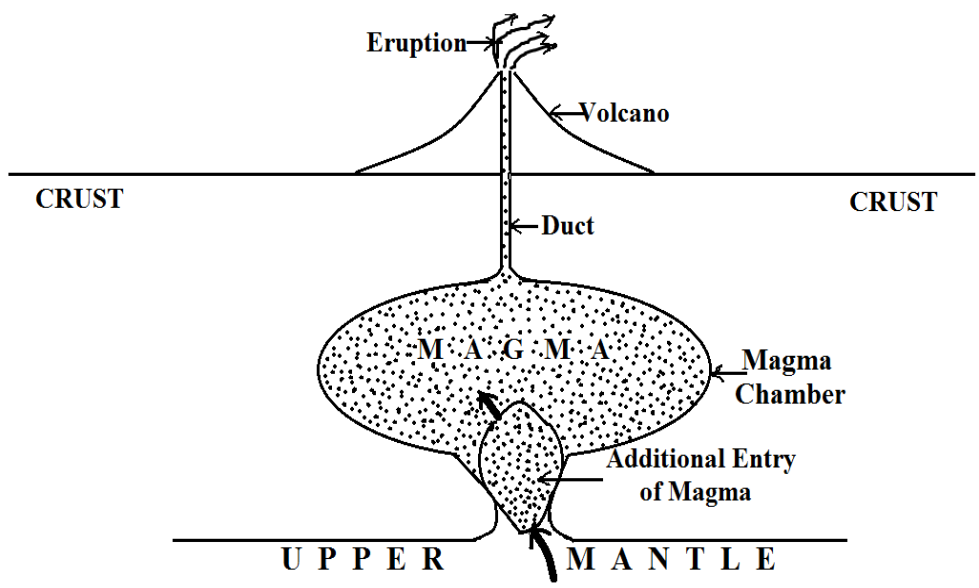

Fig.4 Additional entry of magma from the mantle into the magma chamber of a volcano

Mass of magma already in the chamber $=$ Volume $\mathrm{x}$ Density $=10^{13} \times 2600=26 \times 10^{15} \mathrm{~kg}$; It should be noted that there will be no increase in temperature, that is the temperature at the upper mantle is almost equal to the temperature at the entry of the magma chamber. Moreover, for such a high temperature 1200 ${ }^{\circ} \mathrm{C}$, some increase or decrease of 10 degrees is not going to affect.

$$
\text { Now, mass of additional magma }=\mathrm{m}^{1}=\left(\frac{1}{100}\right) \text { of } 26 \times 10^{15} \mathrm{~kg}=26 \times 10^{13} \mathrm{~kg}
$$

Entropy $S_{2}$ of this additional magma $=m^{1} \times c=26 \times 10^{13} \times 1450=377 \times 10^{15}=3.77 \times 10^{17}$, That is,

$$
\mathrm{S}_{2}=3.77 \times 10^{17} \frac{\mathrm{J}}{\mathrm{K}}
$$

which is one-hundredth of $S_{1}$. 


\section{International Advanced Research Journal in Science, Engineering and Technology}

Vol. 6, Issue 7, July 2019

Now, let us work out the total entropy after the entry of additional magma.

Total mass $=\left(26 \times 10^{15} \mathrm{~kg} ;\right)+\left(26 \times 10^{13} \mathrm{~kg}\right)=2.626 \times 10^{16} \mathrm{~kg}$

The total entropy, $S_{3}=2.626 \times 10^{16} \times$ specific heat

$$
=\left(2.626 \times 10^{16}\right) \times 1450=3.8077 \times 10^{19}=380.77 \times 10^{17}
$$

Therefore $S_{3}=380.77 \times 10^{17} \frac{\mathrm{J}}{\mathrm{K}}$

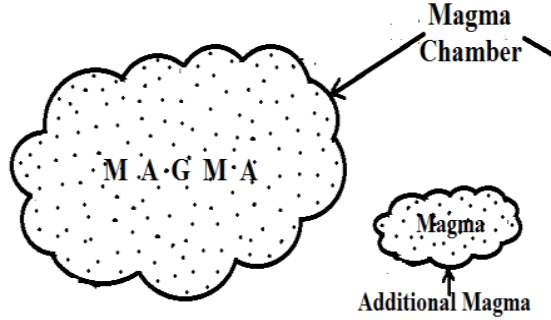

ENTROPY

ENTROPY

$$
\begin{aligned}
\mathrm{S}_{1}=377 \times 10^{17} \frac{\mathrm{J}}{\mathrm{K}} & \mathrm{S}_{2}=3.77 \times 10^{17} \frac{\mathrm{J}}{\mathrm{K}} \quad \mathrm{S}_{3}=380.77 \times 10^{17} \frac{\mathrm{J}}{\mathrm{K}} \\
\mathrm{S}_{3}= & \left(\mathrm{S}_{1}+\mathrm{S}_{2}\right) \quad \ldots \ldots \ldots(13)
\end{aligned}
$$

Fig.5 Illustration of entropy before and after entry of additional magma

\section{CONVECTION IN THE MAGMA CHAMBER}

4. Normal and steady Convection in the Magma Chamber: At equilibrium states, the magma in the chamber is a well set thermodynamic system maintaining constancy of temperature due to normal and steady convection. Steady convection exists as the magma at lower part being near the upper part of the mantle is at a high temperature and hence of low density. The low density magma rises above meet with the layers of crust and get cooled. The cooled magma with a slightly low temperature becomes lighter and comes down and again becomes hot and moves up. This is a normal and steady convection and is stable existing in all magma containers including the mantle@. Any thermal imbalance such as increase of temperature due to entry of fresh magma from the mantle shall create the following:

* Increase of Entropy of magma in the chamber creating more disorder and leading to eruption

* The instability of convection leads to turbulence in the magma chamber leading to eruption. The first of the above can be dealt with elementary thermodynamics specially the concept of entropy whereas the second one needs rigorous mathematical treatment using equations of Fluid Mechanics of Plasma Physics.

@Instability of convection of magma in the mantle leads to tectonic plate movements causing earthquakes. Readers, if interested, may go through a Research Paper by the same author: "Mantle Convection and Plate Tectonics - A Primary Cause for Earthquakes" - International Journal of Engineering Research and Development e-ISSN: 2278-067X, p-ISSN: 2278-800X, www.ijerd.com Volume 12, Issue 3 (March 2016), PP.10-21

\section{THE ERUPTION}

5.The Eruption: The causes of volcanicity and volcanic eruption can include: (Elsewhere from Review of Literature):

- Increased quantity of magma in the mantle leading to increase to pressure pushing this magma out wards.

- Presence of fissure and cracks allowing magma to move towards the crust.

- Increase in the temperature of magma inside making the magma very light to move along a crack. 


\section{International Advanced Research Journal in Science, Engineering and Technology}

Vol. 6, Issue 7, July 2019

The author adds, in addition to the above:

The moment an additional mass of magma of entropy $3.77 \times 10^{17} \frac{\mathrm{J}}{\mathrm{K}}$ from the mantle enters the magma chamber (Fig.4), it is like an unwanted guest creating more trouble and chaos in the system. The entry does not create any appreciable increase in volume of the chamber even though slight increase is shown to appear in the Fig.5, it is just an exaggeration. The additional magma, with its own entropy has added more disorder to an already existing disorder in the chamber. The thermodynamic situation in the chamber is such that there is no considerable change in volume nor is there any increase in temperature. The pressure shoots up tremendously as shown in Fig.6

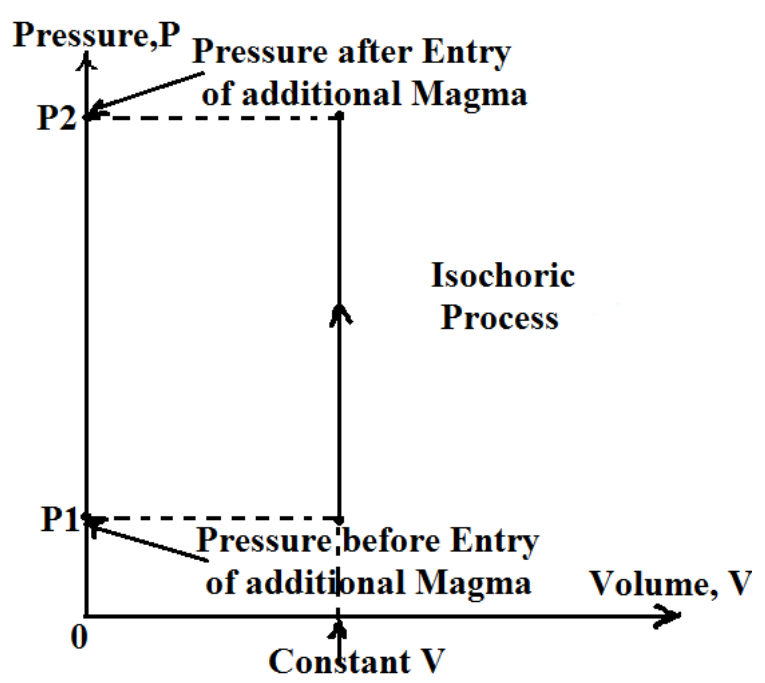

Fig.6 The process in the chamber before an Eruption

by a vertical line at constant volume. We cannot apply ordinary gas laws. The process is an isochoric process where the isothermal of the Boyle's law gets modified to a straight line upwards. The tremendous pressure with an increase of entropy, creates thermodynamic in-equilibrium and the magma oozes out through the vent. The nature of explosion will depend on the mass and size and hence the entropy of the intruding magma. Such tremendous pressures, sometimes might become so explosive that it may even explode and rupture the magma chamber as it happened recently in the eruption of Anak Krakatao of Indonesia on 23 December 2018.

\section{CONCLUSION}

I have somehow considered an unusual concept of Entropy affecting eruptions. I welcome comments and opinions, if any from readers to my e-mail: nairvca39@gmail.com

Maya Wei-Has [3], a Science writer for National Geographic says, "Volcanoes are Earth's geologic architects. They've created more than 80 percent of our planet's surface, laying the foundation that has allowed life to thrive. Their explosive force crafts mountains as well as craters. Lava rivers spread into bleak landscapes. But as time ticks by, the elements break down these volcanic rocks, liberating nutrients from their stony prisons and creating remarkably fertile soils that have allowed civilizations to flourish."

Can we compare the situation in the chamber after the entry of magma with the chaos of Edward Lorenz (1917-2008) the famous author of the Chaos Theory and winner of Kyoto Prize? Yes! We can. It is Lorenz's 'Butterfly Effect' Compare the situation with the flap of a butterfly taking place in Brazil creating a tornado in Texas. The entry of additional magma far away inside the Earth is akin to flap of a butterfly causing an Eruption like Tornado on the surface of the Earth. Either the increase of entropy or the instability of convection or even both can trigger an eruption.

I conclude by making a statement:

Volcanic ash may be harmful to the humans, but the "Eruption of a Volcano is a Beauty of Nature" 


\section{International Advanced Research Journal in Science, Engineering and Technology}

Vol. 6, Issue 7, July 2019

\section{REFERENCES}

[1]. Google Search- Specific heat of Magma

[2]. Kin Jorgastin- How Big are Volcano Magma Chambers?, Modern Survival Blog-Jan.11, 2011

[3]. Maya Wei-Haas, A Science writer for National Geographic-Jan.15, 2018

[4]. Nobuo Geshi, Valerio Acocella and Joel Ruch-Evaluating volumes for magma chambers and magma withdrawn for Caldera Collapse, Earth and Planetary Science Letters - Jam. 2014

[5]. Roberts J.K. Heat and Thermodynamics, Blackie and Son Limited, London and Glasgow, 1943 Reprint. Chapter XV Principle of increase of Entropy, p.309-312

[6]. Wikipedia

\section{BIOGRAPHY}

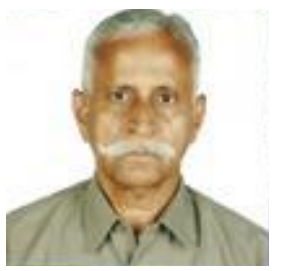

*Dr.(Prof.) V.C.A. Nair (b.15th Aug. 1939) is an Educational Physicist, Counselor, Research Guide and Consultant. He did his Masters in Physics from Mumbai University, India and Ph.D. from JJT University, Rajasthan also in India He is a Research Guide and distinguished alumni of JJT University. He is also a Chancellor designated Resource Person in the area of Physics in the University. He has to his credit over 4 decades of teaching Applied Physics in eminent Polytechnics in Mumbai and having taught nearly 16,000 students since 1965. He has published a number of research papers in Physics and Geophysics in International and UGC recognized Journals some of which can be seen in the net 'Google Search' when the name of the author or his e-mail is typed in that style. He is a Life Member of Indian Society for Technical Education which is an all India body. He had been to USA a number of times and visited eminent Universities such as Stanford, Harvard, MIT, 3 Universities of California at Berkeley, Los Angeles and also at Davis, University of Princeton at New Jersey, Roosevelt University at Chicago, University of Chicago and University of San Francisco. At present Dr. Nair is a Research Guide for Physics at Shri JJT University, Rajasthan-333001, India. He is member of the Editorial Board of this Journal. His Ph.D. Thesis is in Geophysics and he is working on topics such as Tides, Clouds, Global Warming and Climate Change. - Editor.

*nairvca39@gmail.com. 